Fernández, Daniel. Defectos de diseño del euro: problemas inherentes al Banco Central Europeo.

\title{
DEFECTOS DE DISEÑO DEL EURO: PROBLEMAS INHERENTES AL BANCO CENTRAL EUROPEO
}

\author{
DANIEL FERNÁNDEZ \\ Universidad Francisco Marroquín \\ d.fernandezm@ufm.edu
}

Fecha de recepción: mayo de 2014

Fecha de aceptación: agosto de 2014

\begin{abstract}
RESUMEN
En medio de la Gran Recesión surgen constantes dudas acerca del diseño de la moneda única europea. El objetivo de este artículo es establecer que problemas sobrevenidos podrían haber sido evitados con un diseño de la moneda o de las instituciones monetarias más eficiente. La mayor parte de omisiones por parte de los diseñadores del Euro vienen de infravalorar el mecanismo de redistribución que puede llegar a suponer el engranaje monetario. No menos importante es su posible uso como transmisor de riesgos tanto del sector privado al público como entre diferentes Estados. Por último se hace alusión a los problemas monetarios derivados y también olvidados por parte del legislador que causan el arbitraje de tipos de interés a diferentes plazos temporales y los excesos de crédito a largo plazo sin mecanismo preventivo que límite su expansión.
\end{abstract}

PALABRAS CLAVE: dinero, liquidez, medios de pago, crédito.

\begin{abstract}
In the midst of Great Recession come up in Europe many doubts about the design of the European currency. The aim of this paper is to establish what kind of issues could have been avoided with a more efficient currency and monetary institutions design. Most of these oversights are due to underestimate redistribution function that could carry on through monetary system or the transfer of risk that could happen from private sector to public sector or between different States inside the European Monetary Union. Finally we treat monetary issues derived from interest rate arbitrages between different terms and the long term credit abuse and the inexistence of a mechanism to limit its expansion.
\end{abstract}

KEYWORDS: monetary system, liquidity, means of payment, credit.

JEL: F33, F36, G28.

\section{INTRODUCCIÓN}

Desde que Mundell escribiera su famoso artículo (Mundell, 1961) mucho se ha escrito y discutido sobre la estabilidad de los sistemas en los que coexiste una 
Fernández, Daniel. Defectos de diseño del euro: problemas inherentes al Banco Central Europeo.

misma moneda en áreas supranacionales y sobre los problemas de estabilización monetaria que podrían existir en las mencionadas áreas.

El presente trabajo es un intento de vislumbrar los problemas de diseño que arrastra la principal moneda supranacional que existe en la actualidad y ver como los criterios de Mundell podrían ser necesarios pero no suficientes para una estabilización monetaria permanente.

\section{EL EURO COMO FORMA DE CRÉDITO QUE PERMITE FINANCIAR A LOS ESTADOS MIEMBROS ${ }^{1}$}

El primero de los puntos fue en realidad parcialmente previsto por parte de los diseñadores del $€$ al introducir los criterios de convergencia como necesarios para que un Estado miembro pudiera ingresar en la Unión Monetaria Europea ${ }^{2}$. En concreto los criterios que evidencian la preocupación del legislador por evitar que la moneda única sea un elemento de financiación son el establecimiento del déficit inferior al $3 \%$ del producto interior bruto y el establecimiento de un techo a la deuda pública del $60 \%$.

Los Estados con autonomía monetaria normalmente tienen dos opciones no excluyentes a la hora de emitir deuda pública. La primera sería emitir los pasivos estatales y acudir al mercado para que éste financie el exceso de gasto público. La segunda sería acudir a su propio banco central para que éste monetice la deuda pública ${ }^{3}$, esto es, el banco central financia al Estado comprando la deuda pública y este a la vez se financia expandiendo la base monetaria ${ }^{4}$.

En el caso de las monetizaciones el que termina siendo partícipe de la deuda pública y el último financiador de ella sería todo demandante de medios de pago emitidos por el banco central ${ }^{5}$. Cualquier inversor que decida mantenerse líquido en realidad estaría financiando al Estado a pesar de que su intención es bien distinta y en realidad contraria 6 . Al ser el banco central el vehículo intermedio en realidad la naturaleza de la financiación del Estado quedaría oculta "tras el velo monetario"7.

Al introducir la deuda pública en el mecanismo monetario se estaría aprovechando la demanda monetaria para crear una demanda adicional y artificial sobre la deuda

\footnotetext{
${ }^{1}$ La idea original se encuentra en (Bagus, 2010) aunque en el presente texto se le da un enfoque diferente.

${ }^{2}$ Véase Tratado Unión Europea (European Community, 1992)

${ }^{3}$ Sin perjuicio de que existan otras taxonomías como por ejemplo emitir deuda en moneda nacional y moneda extranjera.

4 En realidad los dos métodos pasarían siempre por el primero puesto que en la mayoría de países la monetización directa de deuda pública está prohibida.

${ }^{5}$ Demanda en el sentido que indica Cannan, es decir atesoramiento de medios de pago (Cannan, 1921).

${ }^{6}$ Mantenerse líquido financieramente implica que se pretende conservar poder adquisitivo en espera de una mejor oportunidad de inversión, es decir ninguna de las oportunidades actuales ofrecería un buen retorno esperado al inversor que pretende conservar su liquidez.

${ }^{7}$ Como diría David Hume, ensayos económicos (Hume, 1752).
} 
Fernández, Daniel. Defectos de diseño del euro: problemas inherentes al Banco Central Europeo.

pública que permite disminuir el tipo pagado por la misma. El financiador último de la deuda pública no es consciente de la posición acreedora que ostenta.

Mientras la deuda pública de los estados miembros se financiaba con las monedas nacionales los que soportaban el coste de la monetización eran los ciudadanos nacionales ${ }^{8}$. En el momento en que la deuda pública es nacional y la moneda pasa a ser trasnacional existe la posibilidad de abusar del mecanismo monetario por parte de cualquier Estado. Los Estados pueden estarían en posición de emitir deuda pública y encontrar financiadores inconscientes por toda la Unión Monetaria Europea.

Con autonomía monetaria los Estados pueden crear esta demanda artificial para su deuda pública pero tienen un límite para la misma; la aceptación de los pasivos de su banco central, esto es podría llegar a existir un exceso de oferta de pasivos del banco central que no encontraran demanda, por lo que al ser éstos utilizados como medio de pago ${ }^{9}$ se filtran al mercado como mayores disponibilidades sobre bienes presentes apareciendo por tanto la inflación. En suma si aumentan los pasivos monetarios del banco central por encima de su demanda y por encima de la capacidad de la economía para crear nueva riqueza la moneda pierde poder adquisitivo. Esta pérdida de poder adquisitivo puede provocar que marginalmente su demanda empiece a descender provocando un efecto de realimentación en el que la disminuida demanda provoca ulteriores caídas del poder adquisitivo del pasivo monetario $^{10}$. Este círculo vicioso puede llegar al punto que se rechace la moneda si se generaliza su uso como medio de financiación último de la deuda pública, esto es, puede aparecer una hiperinflación.

El mecanismo monetario europeo posibilita que la deuda monetizada de los Estados nacionales tenga una demanda mucho mayor al ser utilizados los pasivos del Banco Central Europeo no ya por la masa limitada de ciudadanos nacionales sino por los de todos los países integrantes de la Unión Monetaria Europea ${ }^{11}$. Es decir la monetización de la deuda pública sería un mecanismo que permite externalizar los costes de la misma desde los ciudadanos nacionales a los ciudadanos que utilizan la moneda común. Los Estados nacionales podrían endeudarse a un tipo de interés muy inferior al que les permite su situación gracias a que el mecanismo monetario europeo les da acceso a una fuente de financiación mucho más profunda que el mecanismo monetario nacional.

\footnotetext{
${ }^{8}$ Es de esperar que la mayor demanda de una moneda venga de los ciudadanos nacionales que son los que pueden usarla para intercambiar bienes y servicios dentro de las fronteras. Medidas como el curso forzoso o el pago de impuestos en moneda nacional apuntalan la demanda nacional monetaria nacional pero no tienen efecto fuera de las fronteras.

${ }^{9}$ Además de como reserva bancaria por el sistema financiero.

${ }^{10}$ El efecto a corto plazo en presencia de inflación es que aumenta la demanda de dinero si asumimos que la demanda de saldos monetarios reales es constante. A largo plazo el efecto es el contrario, existirá una huida de activos que pierden valor.

${ }^{11}$ Es necesario incluir además la demanda que el $€$ tiene como reserva internacional.
} 
Fernández, Daniel. Defectos de diseño del euro: problemas inherentes al Banco Central Europeo.

Con monedas nacionales aquel país que más satisfaga su demanda de crédito a largo plazo con cargo pasivos monetarios y no a oferta de crédito a largo plazo más vería depreciarse su divisa. Una vez desaparecen las monedas nacionales este mecanismo desaparece también creando de forma no intencionada un incentivo poderoso por parte de todos los integrantes de la zona Euro a expandir su crédito con cargo al ahorro a corto plazo de los demás antes de que los demás hagan lo propio $^{12}$.

Es por ello que entre los criterios de convergencia se establecen límites tanto al déficit público como a la cantidad de deuda pública viva que puede manejar un Estado. Los criterios de convergencia podrían ser vistos como un límite a la externalidad que en un Estado miembro de la Unión Monetaria Europea puede ejercer sobre los demandantes de moneda de otros Estados.

\section{EL $€$ COMO MECANISMO DE TRANSMISIÓN DEL RIESGO DEL SISTEMA FINANCIERO}

Históricamente el Banco Central ha cargado sobre sus espaldas con la función de hacer de prestamista de última instancia del sector financiero ${ }^{13}$. En la medida en que los criterios para elegir el colateral exigible o bien para elegir la compra de activos al sector financiero sean los suficientemente exigentes la transmisión de riesgos al Banco Central será mínima ${ }^{14}$.

Para minimizar la transmisión de riesgos los activos objeto de la política de descuento serían instrumentos que por su propia naturaleza conllevan una posibilidad de impago mínima, esto es papel comercial a corto plazo y con garantía real materializada en bienes de consumo en alta demanda ${ }^{15}$. Si la posibilidad de impago es mínima también lo es la transmisión de riesgos del sector financiero al Banco Central Europeo.

Por lo tanto, y con objeto de minimizar la transmisión de riesgos la compra de activos o el colateral exigible para las líneas de liquidez ha de evitar ser a largo plazo y se debe evitar también activos especulativos cuyo repago esté en entredicho. Si los activos objeto de la política de descuento son activos a largo plazo o activos con mucho riesgo, el Banco Central Europeo en su aspecto de prestamista de última instancia, actuará también como transmisor del riesgo desde el sistema financiero que lo contrajo ${ }^{16}$ hasta los usuarios de sus pasivos, esto es cualquier tenedor de Euros. Dicho de otra manera, una mala elección del colateral permite transferir el

\footnotetext{
${ }^{12}$ En un evidente caso de tragedia de los bienes comunales. Véase (Hardin, 1968)

${ }^{13}$ Véase (Bagehot, 1873)

${ }^{14}$ La transmisión de riesgo nunca será nula puesto que el Banco Central pierde liquidez al comprar o extender créditos contra activos que producen un interés. Cualquier agente que modifica su posición mejorando su rentabilidad y empeorando su liquidez asume un riesgo de crédito por pequeño que este sea. Por lo tanto esta transmisión de riesgo del sistema financiero al Banco Central nunca podrá llegar a ser nula, aunque si puede quedar reducida a la mínima expresión.

${ }^{15}$ Véase doctrina de las letras reales, (Smith, 1776)

${ }^{16}$ Con el consiguiente aumento de la rentabilidad asociado a la mayor asunción de riesgos.
} 
Fernández, Daniel. Defectos de diseño del euro: problemas inherentes al Banco Central Europeo.

riesgo asumido por un agente que ha maximizado su rentabilidad mediante dicha asunción de riesgos hasta otro agente que pretendía mantenerse ajeno de ese riesgo y de su mayor rentabilidad asociada. Mediante el mecanismo monetario sin embargo se hace partícipe de un riesgo a agentes que nunca pretendieron tomarlo.

Una monetización indiscriminada de activos del sector financiero conlleva una externalidad negativa proveniente del sector financiero para con la sociedad. La externalidad la permite y arbitra el Banco Central al ser el ente que canaliza los activos desde el sector financiero hacia los usuarios de la moneda. Se producen todos los elementos típicos de una externalidad. Por una parte, y ante la expectativa de no cargar con los posibles costes asociados al fallo del crédito se concede crédito con un riesgo mayor y por otra parte los costes los sufren los tenedores de Euros al ver disminuido el poder adquisitivo de éstos ${ }^{17}$.

\section{EL EURO COMO MECANISMO DE TRANSMISIÓN DEL RIESGO SOBERANO}

El Euro puede supone una externalización del riesgo del sector financiero de la misma forma que puede suponer una externalización del riesgo inherente a las condiciones financieras de los Estados pertenecientes a la UME. De hecho se podría decir que en cierta medida.

Las vicisitudes de las diferentes haciendas públicas y el vínculo a sus propios bancos centrales hacían que antes del Euro las tensiones referentes a las cuentas públicas se reflejaran primordialmente en el tipo de cambio. Los países con cuentas públicas ordenadas disfrutan de estabilidad monetaria y los países con desequilibrios presupuestarios sufren periodos inflacionarios graves.

Con la entrada en el Euro las tensiones en los mercados de tipo de cambio se trasladan al mercado de bonos soberanos. Las primas de riesgo tienden a reflejar la misma información que antes de la unión monetaria reflejaban los tipos de cambio. Si los criterios de convergencia son respetados y el acceso al mecanismo monetario para conseguir financiación es restringido, entonces las primas de riesgo informan del estado de las cuentas de los gobiernos dentro de la UME. La transmisión de riesgos soberanos se mantiene bajo un estricto control siempre que el mecanismo monetario se mantenga lo más alejado posible de la financiación de los Estados.

En la medida que los criterios de convergencia se relajan, los Estados que más los incumplen externalizan sus costes sobre el resto de ciudadanos de la zona Euro.

Los Estados favorecen la monetización de su propia deuda pública por encima de otros activos mediante una serie de medidas ${ }^{18}$. Mediante tales medidas se crea una demanda artificial de deuda pública por parte del sector bancario que tiende a elegir

\footnotetext{
${ }^{17}$ Activos de peor calidad en el balance del BCE implican pasivos (Euros) con un valor inferior.

${ }^{18}$ Haircut o criterios de solvencia Basilea. Véase (European Central Bank) o (Bank of International Settlements, 2010) 
Fernández, Daniel. Defectos de diseño del euro: problemas inherentes al Banco Central Europeo.

un pool de activos mucho más tendente a incorporar deuda soberana que cualquier otro tipo de activo emitido por entidades privadas.

Dadas las condiciones de creación de medios de pago por parte del $\mathrm{BCE}^{19}$ que conllevan una monetización de deuda pública ${ }^{20}$.

Estados europeos con cuentas sólidas soportan el riesgo de Estados europeos con cuentas deterioradas.

\section{4. ¿POR QUÉ LA POLÍTICA DE DESCUENTO DEL BCE NO FUNCIONA?}

La política de descuento de los bancos centrales fue desarrollada en el siglo XIX ${ }^{21}$ en la Inglaterra victoriana. Si bien los bancos ingleses de la época no eran extremadamente respetuosos en el manejo de su liquidez, el sistema financiero ostentaba un grado de liquidez ${ }^{22}$ muy superior al actual. La política de descuento presupone una estructura bancaria líquida para su correcto funcionamiento ${ }^{23}$.

Si las instituciones financieras inmovilizan a largo plazo los fondos que reciben a la vista o a corto plazo se produce una degradación paulatina de su liquidez tendente a maximizar su rentabilidad ${ }^{24}$. Con dicha práctica se adiciona el riesgo de liquidez o de refinanciación continua en el mercado al riesgo de mercado inherente a la práctica bancaria, esto es, el riesgo de crédito.

Como consecuencia de la iliquidez de los activos bancarios la política de descuento del BCE se ve seriamente afectada. Si los activos que adquiere el sistema bancario son a largo plazo las posibilidades que tienen los Bancos Centrales de influir en la cantidad de crédito y medios de pago en la economía son muy limitadas.

Un sistema bancario líquido sería aquel en el que las instituciones financieras intermedian cada tipo de interés en función de su plazo ${ }^{25}$ y que por lo tanto tienden a igualar oferta y demanda de capital con el mismo perfil temporal llegando a un tipo

\footnotetext{
${ }^{19}$ Es decir de base monetaria

20 En realidad la forma de monetizar activos se realiza por parte de sistema financiero y este recibe refinanciaciones del BCE cuyo colateral exigible es el propio activo. Aquí es donde se produce una ulterior preferencia inducida hacia la deuda pública que tiene todo banco central; el "haircut" o cantidad del valor nominal del título que no refinancia el banco central es mucho mayor para el sector privado que para el público por lo que el sector financiero tiende, a igualdad de condiciones, a extender crédito al sector público con preferencia al sector privado. Para ver el "haircut" aplicado por el BCE, (European Central Bank)

${ }^{21}$ Véase (Bagehot, 1873)

${ }^{22}$ Adecuación entre flujos de caja de las diferentes masas patrimoniales.

${ }^{23}$ Véase (Palyi, 1936)

${ }^{24}$ Véase mi propio artículo, curva rendimientos

${ }^{25}$ Lo más correcto sería decir que las instituciones financieras intermedian cada tipo de interés en función de su plazo y de su riesgo. Por motivos expositivos nos limitaremos a analizar la liquidez del sistema bancario tan sólo en función de su plazo.
} 
Fernández, Daniel. Defectos de diseño del euro: problemas inherentes al Banco Central Europeo.

de interés diferente en función del plazo ${ }^{26}$. Es decir estas instituciones invierten sus fondos a un plazo similar al que lo piden prestado concediendo crédito a un plazo semejante al que otros agentes le conceden crédito.

En el sistema bancario líquido la cantidad de medios de pago emitidos está asociada indisolublemente a inversiones a corto plazo, en concreto a letras de cambio auto liquidables $^{27}$. Cuando el Banco Central pretende restringir la oferta monetaria puede aumentar el tipo de descuento bancario y de manera casi automática los efectos presentados a descuento se restringen drásticamente y con ello la cantidad de medios de pago en la economía. Un mayor tipo descuento implica un menor descuento de letras lo que conlleva menor creación de medios de pago contra esas letras. Los medios de pago van desapareciendo a medida que las letras vencen, van siendo pagadas y marginalmente no se produce una renovación del crédito circulante debido al mayor tipo de descuento. Por lo que cualquier tendencia inflacionista podría ser rápidamente frenada por un Banco Central. La respuesta en la cantidad de medios de pago disponibles ante un cambio es el tipo de descuento del Banco Central es muy rápida y efectiva. La efectividad de la política de descuento presupone y necesita de una estructura bancaria líquida.

De igual manera una bajada en el tipo de descuento del Banco Central Europeo provocaría casi automáticamente un mayor descuento de letras. Los comerciantes que hubieran mantenido hasta vencimiento sus efectos acuden al sistema bancario a descontarlos. La bajada de tipos hace que el coste financiero del descuento sea menos oneroso y marginalmente provoca que el tipo implícito de la reinversión en el propio negocio sea mayor que el coste financiero de anticipar el pago del efecto comercial antes de la fecha de vencimiento. Es decir aumenta marginalmente la reinversión puesto que disminuye marginalmente el coste del descuento por debajo de la ganancia esperada de girar un nuevo efecto.

Un sistema bancario ilíquido sería aquel en el que el objeto de su intermediación no sería ya el tipo de interés de un plazo concreto sino el spread entre los tipos a diferentes plazos. Las instituciones financieras se dedican a inmovilizar a largo plazo los capitales recibidos a corto plazo. Provocan que la oferta de capital a corto plazo se traslade a satisfacer la demanda de capital a largo plazo. En otras palabras se produce una masiva financiación de proyectos a largo plazo con cargo a los fondos que se deben hacer disponibles a corto plazo.

En el caso de un sistema bancario ilíquido existen varios problemas que frenan mucho la efectividad de la política de descuento. El primero de ellos es que el tipo de descuento tan sólo ejerce una influencia indirecta en los tipos de interés a más largo plazo.

\footnotetext{
${ }^{26}$ Creciente con el plazo y consecuente con la curva de rendimientos. Esto es debido a la preferencia por la liquidez y al mayor riesgo asociado a inversiones con un perfil temporal más alejado por mayor dificultad en la previsión de las circunstancias futuras que permitirán atender al préstamo.

${ }^{27}$ Letras cuyo colateral son bienes presentes en alta demanda, es decir nuevas disponibilidades (dinero bancario) cuya garantía real son bienes presentes. Véase la doctrina de las letras reales (RBD), (Smith, 1776)
} 
Fernández, Daniel. Defectos de diseño del euro: problemas inherentes al Banco Central Europeo.

Un segundo problema que frenaría la efectividad del tipo de descuento sería el carácter a largo plazo de los activos que mayoritariamente posee el sistema bancario. Una subida en el tipo de descuento del Banco Central provocaría en principio un aumento, siempre con retardo, en los tipos de interés a largo plazo. Esta subida pone freno a la demanda de nuevo crédito a largo plazo y con ello a la creación de nuevos medios de pago en la economía ${ }^{28}$. Los medios de pago también van desapareciendo a medida que los créditos van siendo repagados pero a diferencia de lo que acontecía en el caso del sistema bancario líquido los activos son a muy largo plazo por lo que los medios de pago tienden a permanecer en la economía un periodo mucho mayor, concretamente hasta que el activo se repague $^{29}$.

Por lo tanto un sistema bancario líquido la cantidad de medios de pago reacciona rápidamente ante cambios en la política de descuento del Banco Central mientras que el sistema bancario ilíquido es mucho más lento para restringir sus medios de pago al afrontar los problemas de retardo del tipo de descuento a los de tipos de interés a largo plazo y el problema de ligar la cantidad de medios de pago a la amortización de activos a muy largo plazo.

La bajada de tipos en un sistema líquido podría ser catalogada como una medida de estímulo no inflacionaria y con un retardo ínfimo. Provoca un efecto positivo sobre el comercio al aumentar la velocidad de circulación monetaria sin aumento de precios. Los nuevos medios de pago vienen coletarizados por bienes ya producidos y en alta demanda por lo que bajadas del tipo de descuento no tienen efecto inflacionario. Un sistema bancario que respete el principio de la liquidez no puede expandir los medios de pago por encima del capital circulante ${ }^{30}$, es decir no puede existir inflación ya que los medios de pago recién creados tienen su contraprestación y límite en la masa de bienes presentes líquidos. Es decir una gran bajada del tipo de descuento del BCE no tendría un gran impacto si no existe colateral válido para ser monetizado, es decir si no existe demanda de crédito al plazo requerido su mayor oferta no encontraría acomodo en el mercado y por lo tanto no tendría nunca un efecto inflacionario. En otras palabras los estímulos del BCE tendrían como límite y salvaguarda las condiciones crediticias del mercado.

La bajada de tipos en un sistema ilíquido podría ser catalogada como una medida de estímulo inflacionaria con un gran retardo.

\section{POLÍTICA DE DESCUENTO Y DESTRUCCIÓN TEJIDO PRODUCTIVO}

La bajada del tipo de descuento en un sistema bancario ilíquido podría ser catalogada como una medida de estímulo inflacionaria ya que al monetizar activos a

\footnotetext{
${ }^{28}$ Este aumento se deja de producir precisamente porque el sistema bancario deja marginalmente de emitir nuevos medios de pago cuyo colateral es el activo a largo plazo también marginalmente deja de adquirir.

${ }^{29}$ Nótese que no tiene porqué ser hasta que llegue el vencimiento. Una quiebra del emisor del activo conlleva automáticamente una destrucción de los medios de pago asociados a él. Asimismo un aumento del ahorro tendente a amortizar deuda anticipadamente también provoca disminución de pasivos monetarios.

${ }^{30}$ Véase (Smith, 1776) 
Fernández, Daniel. Defectos de diseño del euro: problemas inherentes al Banco Central Europeo.

largo plazo ${ }^{31}$ se crean nuevas disponibilidades presentes sobre bienes presentes sin que haya contraprestación por el lado de los bienes. El aumento de la moneda no se ve reflejado en un aumento de los bienes de consumo. Los bienes que actúan como colateral no son capital circulante sino capital fijo ${ }^{32}$. Se produce una descoordinación monetaria tendente en un primer momento a ser inflacionaria y en el momento futuro en que el capital fijo madure deflacionaria ${ }^{33}$.

Bajadas del tipo de referencia en sistema ilíquido conlleva una bajada de paulatina de los tipos a largo plazo a medida que el sector bancario va arbitrando la curva de rendimientos y traslada disponibilidades hacia proyectos de inversión a largo plazo. Estas bajadas provocan una sensación de euforia económica, aumenta la inversión a largo plazo y con ello las expectativas de crecimiento futuro. Sin embargo esta inversión a largo plazo se encuentra por encima del ahorro disponible a largo plazo y está en parte sostenida con ahorro a corto plazo. La mayor inversión a largo plazo encuentra entonces su contraprestación en una deficiente inversión a corto plazo ya que parte de ese ahorro se encuentra inmovilizado en proyectos productivos a largo plazo. Se produce una sobreinversión en capital fijo y una infrainversión en capital circulante cercano al consumo. A medio plazo se produce un cuello de botella en el capital circulante, fruto de su deficiente oferta por infrainversión que provoca una pugna por los recursos por parte de los dueños de los factores productivos fijos y desencadena un alza en el precio de las materias primas que mina los márgenes del capital fijo y que se traslada a precios sobre el consumo. Es entonces cuando la política de descuento pretende restringir la oferta monetaria con el fin de luchar contra la inflación. Esta subida de tipos en la medida en que se va trasladando al tipo de largo plazo ahoga todavía más la rentabilidad del capital fijo pudiendo llegar a provocar la destrucción del tejido productivo.

La subida del tipo de descuento en un sistema líquido es rápida y efectiva para frenar expansiones monetarias como ya hemos visto. Más importante es que el sistema bancario líquido hace que estas subidas de tipos no sean necesarias por no ser el sistema en sí inflacionario. Además el hecho de estar los flujos de ahorro coordinados temporalmente permite que los tipos a largo estén en gran parte esterilizados frente a cambios en los tipos a corto ${ }^{34}$.

La subida del tipo de descuento en un sistema ilíquido es lenta y muchas veces completamente ineficiente para retirar disponibilidades del mercado al estar estas vinculadas a inversiones a largo plazo y ser imposible liquidarlas a corto plazo. Al ser este sistema intrínsecamente inflacionario provoca la necesidad del descuento que se traslada a lo largo de toda la curva de tipos por arbitraje del sistema bancario. Al

\footnotetext{
${ }^{31}$ Es decir bienes futuros que no están disponibles y que no lo estarán en un futuro próximo.

${ }^{32} \mathrm{Y}$ por tanto no podrán convertirse en bienes de consumo hasta pasado un gran lapso temporal.

${ }^{33}$ Ya sea por repago del principal una vez madurada la inversión o por su impago si la inversión es fallida. En cualquiera de los dos casos la supresión de medios de pago lleva aparejada una tendencia deflacionaria.

34 Nunca serán completamente compartimentos estancos ya que mayor tipo de descuento puede mover marginalmente a ahorradores hacia el corto plazo. Sin embargo al estar casados plazos ahorro e inversión ex ante elimina el riesgo de liquidez o refinanciación por parte de los inversores a largo plazo que ya han cerrado completamente su financiación.
} 
Fernández, Daniel. Defectos de diseño del euro: problemas inherentes al Banco Central Europeo.

subir los tipos a largo plazo se ahoga la rentabilidad del capital a largo plazo y provoca destrucción de tipo productivo. La subida del tipo de descuento sólo provoca disminuciones de la actividad económica en un entorno en el que el sistema bancario es ilíquido.

En otras palabras, el sistema bancario ilíquido traslada factores desde posiciones económicas óptimas a subóptimas ${ }^{35}$, descoordinando la estructura productiva y provocando inflación que al intentar ser combatida por las autoridades monetarias ocasiona una destrucción del tejido productivo de la sociedad al ahogar las rentabilidades del capital a largo plazo.

\section{INEXISTENCIA MECANISMO PARA EL FRENO DE LA INVERSIÓN A LARGO PLAZO}

En el diseño del Euro llama la atención la inexistencia de un mecanismo para frenar la expansión del crédito a largo plazo. Casi desde la fundación de los primeros bancos los teóricos pueden establecer una relación entre la cantidad de crédito y el crecimiento económico ${ }^{36}$. Es por ello que en principio el BCE no tiene a su disposición un mecanismo que permita al crédito privado dejar de expandirse indefinidamente cuando la economía se encuentra en la parte alta del ciclo económico ${ }^{37}$.

La igualdad entre la inversión y el ahorro es una necesidad lógica ${ }^{38}$. Es imposible que los agentes económicos inviertan algo que no ha sido ahorrado con anterioridad. Para que un agente realice una inversión es necesario temporal y lógicamente que otro agente ${ }^{39}$ haya ahorrado los recursos objeto de inversión. El ahorrador libera recursos y el inversor los utiliza, no puede invertirse nada que no haya sido ahorrado previamente, la relación entre el ahorro y la inversión es inequívocamente de igualdad $^{40}$.

\footnotetext{
${ }^{35}$ Desde inversiones a corto plazo en capital circulante a inversiones a largo plazo en capital fijo. Esto es reflejo del traslado de ahorro a corto plazo para financiar inversiones a largo plazo.

${ }^{36}$ Véase (Dunbar, 1891)

${ }^{37}$ Simplemente porque se asume implícitamente que no hay problemas en la acumulación de crédito.

${ }^{38}$ Por lo tanto la mayoría de economistas austriacos están equivocados cuando afirman que el ciclo económico se produce por una sobreinversión no respaldada en ahorro real, al respecto véase (Rothbard, 1962). Sin embargo existen desarrollos recientes de la teoría austriaca del ciclo donde no se necesita asumir que la inversión crece por encima del ahorro, encontrado el motivo del ciclo en la expansión de la inversión por encima del ahorro disponible al mismo plazo temporal, es decir el germen del ciclo estaría en canalizar flujo de ahorro a corto plazo hacia inversiones a largo plazo, al respecto véase (Rallo, Una aplicación de la teoría del ciclo económico desde la perspectiva de la Escuela Austriaca a la Gran Recesión. Tesis no publicada, 2011)

${ }^{39} \mathrm{O}$ el mismo agente.

${ }^{40}$ Parece muy claro que la inversión no puede ser superior al ahorro, el caso contrario podría parecer más plausible, ahorro por encima de inversión. El caso del atesoramiento parecería ser un ahorro que no provoca demanda de factores productivos y por tanto se trasladaría a factores ociosos. Sin embargo el ahorro podría ser visto como una demanda de bienes de consumo o de proyectos productivos que no existen, es decir es una demanda de una estructura productiva con unas características diferentes a la existente, véase (Rallo, Los errores de la vieja economía: Una refutación de la Teoría General del Empleo, el Interés y el Dinero de J.M. Keynes, 2011)
} 
Fernández, Daniel. Defectos de diseño del euro: problemas inherentes al Banco Central Europeo.

La expansión del crédito concedido a largo plazo en principio no tiene mayores inconvenientes si una vez más asumimos un sistema financiero líquido. En dicho esquema el sistema bancario, como ya ha sido subrayado, realiza una mera función de intermediario en el mercado de capitales entre ofertantes y demandantes de ahorro al mismo plazo temporal. En dicho esquema el ahorro a un plazo temporal tan sólo satisface la demanda de capital al mismo plazo temporal, es decir, se establece un tipo de interés por cada plazo ${ }^{41}$. La expansión del volumen de crédito en este caso afronta dos importantes límites. Por un lado un gran aumento de la demanda de crédito característica de las primeras fases expansivas del ciclo económico conlleva un aumento del tipo de interés siempre que no vaya acompañada de un aumento equivalente del ahorro al mismo plazo temporal. Aquí encontramos el primer obstáculo, la oferta de crédito tiene distintas elasticidades según su plazo temporal, disminuyendo su elasticidad a medida que aumenta su plazo. En otras palabras una mayor demanda de crédito a largo plazo sólo puede ser parcialmente contrarrestada por un aumento siempre limitado del ahorro disponible. Es entonces cuando esa mayor demanda se transforma en un mayor precio, es decir en un tipo de interés más elevado que provoca la propia restricción de esa demanda y la racionalización del uso del crédito a tan sólo los proyectos que mayor valor añadido esperado tienen. El volumen de crédito a largo plazo encuentra un importante obstáculo en una oferta inelástica incapaz de atender a una demanda creciente. El volumen de crédito encuentra un límite cuantitativo que impide la generación de burbujas y especulación excesiva imponiendo un límite a su uso y derivando dicho crédito a sus mejores asignaciones. La mala asignación generalizada de recursos se reduce al mínimo ${ }^{42}$ al cortarse la expansión de crédito de la primera etapa del ciclo antes de que se produzca.

Por el contrario un sistema financiero ilíquido permite sostener un volumen de crédito mucho mayor. Al ser la oferta de crédito a corto plazo muy elástica ${ }^{43}$ y ser esta oferta trasladada a cubrir la demanda de crédito a largo plazo la inversión puede aumentar de forma exponencial sin que exista un freno efectivo a corto plazo para la misma. En este caso la oferta inelástica de crédito a largo plazo no actúa como freno a la inversión por estar financiada con crédito a corto plazo. Tan sólo las restricciones de la oferta de crédito a largo plazo, reflejadas en desacaparamiento de moneda e inflación pondrían coto a la cantidad de crédito en la economía.

En definitiva en algún momento hay que restringir la oferta de crédito. Más crédito se traslada a mayor crecimiento a corto plazo por lo que es complicado pretender cortar la tendencia. Demanda de crédito a largo plazo se restringe por una oferta de crédito inelástica en un sistema libre que hace subir el tipo de interés y casi automáticamente restringe la demanda de crédito a largo plazo. El BCE permite que la demanda de crédito a largo plazo sea satisfecha con cargo a la mucho más

\footnotetext{
${ }^{41}$ Se establece un tipo de interés por plazo y riesgo a pesar de que en este artículo tratemos exclusivamente el aspecto temporal.

${ }^{42}$ Es imposible eliminarla por completo, véase (Lachmann, 1956)

${ }^{43}$ Especialmente la monetaria
} 
Fernández, Daniel. Defectos de diseño del euro: problemas inherentes al Banco Central Europeo.

elástica oferta de crédito a corto plazo o a la vista y en última instancia se satisface la demanda de crédito a largo plazo con pasivos del BCE.

\section{ESTABILIDAD MONETARIA VINCULADA A MARCHA INVERSIONES A LARGO PLAZO}

Históricamente los bancos centrales conseguían estabilizar el poder adquisitivo de sus pasivos de dos formas ${ }^{44}$ :

- Conversión de sus billetes en oro

- Monetizando letras de cambio a corto plazo con colateral en bienes presentes.

El primero de los requisitos conllevaba que ante una sobre emisión los billetes se depreciaban contra el bien presente y el banco central perdía reservas. El segundo requisito garantiza que los billetes no permanecen en circulación mucho tiempo antes de que vuelvan al banco central para ser pagados además de suponer una expansión de medios de pago tan sólo cuando aumentan las necesidades del comercio.

En la medida en que los activos del banco central maduren a corto plazo con los criterios señalados la estabilidad de sus pasivos está vinculada a la buena marcha del comercio minorista de bienes de consumo en alta demanda. Las condiciones en dichos mercados son usualmente muy estables y poco especulativas además de ofrecer una garantía real materializada en un bien presente. La estabilidad de los pasivos cuando el activo es a corto plazo y poco especulativo está garantizada.

Sin embargo, y como hemos venido señalando a lo largo del artículo los balances de los bancos centrales actuales cuentan en su activo principalmente con créditos a muy largo plazo ${ }^{45}$. Estos activos por su propia composición a largo plazo están sujetos a un riesgo de impago mucho mayor. $Y$ es que incluso en activos considerados seguros el hecho de tener un lapso temporal alargado hace que la capacidad de previsión de las condiciones futuras que permitan devolver el préstamo sea incierta y por lo tanto el riesgo asociado es mucho mayor ${ }^{46}$. Además los bienes que se presentan como garantía en caso de impago son bienes futuros ${ }^{47}$ que podrían perfectamente no ser producidos nunca.

Luego al incluir el balance de los bancos centrales activos a largo plazo se está comprometiendo la estabilidad monetaria a la buena marcha de las inversiones que financian esos créditos. Ante una eventual bancarrota del deudor la insolvencia la traslada al acreedor que en última instancia es el banco central y de ahí a todos los usuarios de sus pasivos contaminando toda la economía pudiendo llegar incluso al rechazo de la moneda y la consecuente hiperinflación.

\footnotetext{
${ }^{44}$ Véase (Dunbar, 1891)

${ }^{45}$ Véase (Federal Reserve) (European Central Bank)

${ }^{46}$ Véase (Scherman, 1938)

47 En concreto los bienes que se compromete a entregar el deudor en el futuro y que todavía no han sido producidos
} 
Fernández, Daniel. Defectos de diseño del euro: problemas inherentes al Banco Central Europeo.

\section{CONCLUSIONES}

- El mecanismo monetario tal y como está configurado actualmente es una fuente de financiación de los Estados. En áreas supranacionales esto crea una tensión por acceder a dicha fuente de financiación especialmente en momentos complicados.

- El BCE actúa como transmisor del riesgo financiero desde el sector bancario a los usuarios de la moneda al actuar como prestamista de última instancia sin unos criterios exigentes de elección de colateral.

- El Euro permite transmitir el riesgo soberano desde los países con cuentas públicas saneadas a los países con gran déficit. Mediante el riesgo monetario que significan los segundos los primeros se ven obligados a realizar rescates fiscales.

- La política de descuento como medio para controlar la cantidad de moneda y de forma indirecta la inflación se torna ineficiente si no asumimos un sistema financiero líquido.

- El manejo de la política de descuento puede terminar en ciclo económico si el sistema bancario arbitra la curva de rendimientos y traslada ahorro a corto plazo a financiar inversiones a largo plazo.

- Inexistencia de mecanismo que limite la expansión de crédito en la economía. La demanda de crédito a largo plazo no se satisface con la inelástica oferta de crédito a largo plazo sino con la mucho más elástica oferta de crédito a largo plazo, ello permite aumentar el volumen de crédito muy por encima de lo sostenible a largo plazo. El tipo de interés como precio en el mercado crediticio pierde su carácter coordinador.

- El precio de los pasivos monetarios actuales viene determinado por las condiciones muy inciertas de las inversiones futuros en las cuales se halla inmovilizado tanto el sector bancario como el propio BCE. 
Fernández, Daniel. Defectos de diseño del euro: problemas inherentes al Banco Central Europeo.

\section{BIBLIOGRAFÍA}

Bagehot, W. A. (1873). Lombard Street (14th ed.). (H. Withers, Ed.) London: Henry S.King and Co. Retrieved 1915

Bagus, P. (2010). The Tragedy of the Euro (2nd ed.). Auburn: Ludwig Von Mises Institute. Retrieved 2012

Cannan, E. (1921). The Application of the Theoretical Apparatus of Supply and Demand to Units of Currency. Economic Journal, 453-461.

Dunbar, C. F. (1891). The Theory and History of Banking. New York: G.P. Putnam's Sons.

European Central Bank. (n.d.). Haircut Category. Retrieved from http://www.ecb.europa.eu/mopo/assets/risk/liquidity/html/index.en.html

European Central Bank. (n.d.). Statistical Data Warehouse. Retrieved from http://sdw.ecb.europa.eu/reports.do?node $=10000024$

European Community. (1992). Retrieved from http://www.eurotreaties.com/maastrichtec.pdf

Federal Reserve. (n.d.). Federal Reserve Statistical Release. Retrieved from http://www.federalreserve.gov/releases/h41/current/h41.htm

Hardin, G. (1968). The Tradegy of the Commons. Science, New Series, 162(3859), 1243-1248. Retrieved 2010

Hume, D. (1752). Essays, Moral, Political, and Literary. In D. Hume, Political Discourses.

Lachmann, L. (1956). Capital and Its Structure (2nd ed.). (L. S. Science, Ed.) London: Bell \& Sons.

Mundell, R. (1961). A Theory of Optimum Currency Areas. The American Economic Review(51), 657-665.

Palyi, M. (1936). Liquidity. Minnesota.

Rallo, J. R. (2011). Atesoramiento, ¿un arma de destrucción masiva? Retrieved from http://juanramonrallo.com/2011/07/atesoramiento-\%C2\%BFun-arma-dedestruccion-masiva/

Rallo, J. R. (2011). Los errores de la vieja economía: Una refutación de la Teoría General del Empleo, el Interés y el Dinero de J.M. Keynes. Madrid: Union Editorial.

Rallo, J. R. (2011). Una aplicación de la teoría del ciclo económico desde la perspectiva de la Escuela Austriaca a la Gran Recesión. Tesis no publicada.

Rothbard, M. N. (1962). Man, Economy and State. William Volker Fund and D. Van Nostrand.

Scherman, H. (1938). The Promises Men Live By: A New Approach to Economics. New York: Random House.

Smith, A. (1776). An Inquiry into the Nature and Causes of the Wealth of Nations (5th ed.). (E. Cannan, Ed.) London: Methuen\&Co. Retrieved 1904 